Available online on 15.05 .2020 at http://jddtonline.info
Open Access to Pharmaceutical and Medical Research
undestricted non-commercial use, provided the original work is properly cited

Open Access

Research Article

\title{
A Herb-drug interaction study: Screen the inhibitory effects of Insulin plant extract on rat liver CYP2D6 isoenzyme upon concurrent administration of Aripiprazole
}

\author{
Harshita Gupta1 ${ }^{1}$ Bhagyashree Kamble ${ }^{1 *}$
}

National Institute of Pharmaceutical Education and Research, Ahmedabad (NIPER-A), Opposite Air Force Station, Palaj, Gandhinagar-382355, Gujarat, India

Author Contributions: Both Authors have contributed equally to the science and in editing this article.

\begin{abstract}
Aripiprazole belongs to the atypical antipsychotic category of drug, frequently prescribed for the cure of Psychosis. Cytochrome2D6 (CYP2D 6) is one of the prominent enzymes that play a key role in the metabolism of Aripiprazole and further formation of an active metabolite, Dehydroaripiprazole takes place. Patients under the treatment with this potent moiety have been reported with the high blood glucose level as a side effect. In addition to this, literature suggests that the leaves of Insulin plant (Costus igneus) are usually administered by diabetic patients (2-3 times) to manage the sugar level without concerning to the physicians. There might be probability while concurrent administration of (Aripiprazole and Insulin plant leaves), leaves inhibit the enzyme and ultimately Dehydroaripiprazole exhibit poor pharmacological action. Hence, the present work was done to investigate the inhibitory effect of Insulin plant extract (IPE) on CYP2D6, with the co-administration of Aripiprazole (to examine the changes in a metabolite of Aripiprazole). In order to carry out this protocol firstly, IPE was prepared by the successive extraction method. Methanolic extract of Insulin plant was found enriched with the Quercetin, which was used as a marker to carry out this study. Presence of Quercetin was confirmed with the Ultra-violet spectroscopy (UV) and High-performance liquid chromatography (HPLC) analytical methods. Characterization of Aripiprazole was done with the help of different analytical tools such as: HPLC, melting point, and UV. Aripiprazole alone and with the several dilutions of IPE were incubated using isolated rat liver microsome (RLM) and an alyzed using HPLC. HPLC data demonstrated that the, mixture of IPE+Aripiprazole (herb and drug in liver microsomes), in comparison to Aripiprazole+RLM (alone drug in liver microsomes) has not shown any significant inhibition of the enzyme, and inhibitory concentration (IC50) value found to be $4.49 \mu \mathrm{g} / \mathrm{ml}$. Therefore this study concluded that IPE has shown safe results even at the highest clinical dose after oral administration i.e., 20$1000 \mu \mathrm{g} / \mathrm{ml}$ and did not show any significant CYP2D6 inhibition. Nevertheless, to confirm these observations, inclusion of in vivo studies will be advantageous. As per our knowledge, this is the first attempt made on the detection of Herb- Drug interactions (HDI'S) between Insulin plant and Aripiprazole.
\end{abstract}

Keywords: Herb-drug interactions, Costus igneus, Insulin plant, CYP2D6, Aripiprazole, inhibitory effect, rat liver microsomes

Article Info: Received 02 March 2020; Review Completed 09 April 2020; Accepted 17 April 2020; Available online 15 May 2020

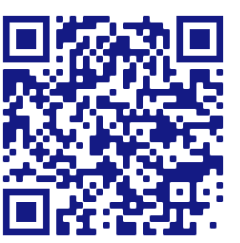

Cite this article as:

Gupta H, Kamble B, A Herb-drug interaction study: Screen the inhibitory effects of Insulin plant extract on rat liver CYP2D6 isoenzyme upon concurrent administration of Aripiprazole, Journal of Drug Delivery and Therapeutics. 2020; 10(3):15-23 http://dx.doi.org/10.22270/jddt.v10i3.3976

*Address for Correspondence:

Dr. Bhagyashree Kamble Assistant professor, National Institute of Pharmaceutical Education and Research, Ahmedabad (NIPER-A), Opposite Air Force Station, Palaj, Gandhinagar-382355, Gujarat, India.

List of abbreviations:

$\begin{array}{lll}\text { Abbreviation } & \text { Expansion } & \text { Abbreviation } \\ \text { ACN } & \text { Acetonitrile } & \text { NADPH } \\ \text { ADME } & \text { Absorption, distribution, metabolism, excretion } & \text { PDA } \\ \text { BSA } & \text { Bovine serum albumin } & \text { Rf } \\ \text { CI } & \text { Costus igneus } & \text { RH } \\ \text { CYP2D6 } & \text { Cytochrome 2D6 } & \text { RLM } \\ \text { FT-IR } & \text { Fourier Transform infrared } & \text { RPM } \\ \text { HDIs } & \text { Herb-drug interactions } & R_{t} \\ \text { HPLC } & \text { High performance liquid chromatography } & \text { TLC } \\ \text { Kcl } & \text { Potassium chloride } & \text { USFDA } \\ \text { LC-MS } & \text { Liquid chromatography- Mass Spectrometry } & \text { UV } \\ \text { MeoH } & \text { Methanol } & \text { WHO } \\ \text { MS } & \text { Mass Spectrometry } & \end{array}$

Expansion

Nicotinamide adenine Dihydrogen phosphate Photo Diode Array Retention factor Relative Humidity Rat liver microsome Revolutions per minute Retention time Thin layer chromatography United State Food and Drug Administration Ultra-violet

World Health Organization 


\section{INTRODUCTION:}

In the era of safe and efficacious drug delivery, modern and herbal drugs are administered simultaneously to achieve the good therapeutic outcomes. In consequences of this, concept of Herb-drug interactions (HDI's) study is very demanding and fascinating. These interactions might alter the Pharmacokinetics (ADME; Absorption, distribution, metabolism excretion) or Pharmacodynamics of the simultaneously administered moieties, and results in inhibition or stimulation of metabolism enzymes ${ }^{1}$. On the basis of survey by World Health Organization (WHO) it is found that globally, $90 \%$ of the population is using herbal to maintain the natural health. As we are aware, people have mindset that herbal therapies are safe in the terms of toxicity and are consumed as home remedies 2,3 . In such cases, a patient is already under Allopathy therapy, should avoid taking Ayurvedic medicaments concurrently or must take after consultation with the doctor. Negligence of together administration can be either more toxic, synergistic or antagonistic impact. But still, there are number of cases where patients do not consult with the physician and suffers from dangerous phenomenon. Many clinically proven likewise; St John's, Ginkgo biloba and Panax ginseng are wellnoted examples in the class of HDI's 4, 5. Many regulatory bodies viz. United State Food and Drug Administration (USFDA) took serious act and recommended to follow the guidelines to avoid HDI 6 . However, deep knowledge of pharmacokinetic profile of both Herb and drug will also enlighten the basic idea to understand the type of interaction, if any ${ }^{7}$. In the same manner, to observe HDI (inhibitory effect) using Aripiprazole as drug and Insulin plant as a herb, we have designed this protocol.

Aripiprazole is a second-generation USFDA approved drug candidate which is used to treat the bipolar disorder ${ }^{8}$. Upon its Oral ingestion, metabolism of the Abilify governs by the CYP2D6, which formed an active metabolite i.e. Dehydroaripiprazole. Some drugs such as Fluoxetine, Paroxetine have been found with the inhibiting potential for the CYP2D6 9, 10. After seeing these huge data (potent inhibitory effects) we have decided to study only inhibitory interaction. Report says, treatment with Abilify causes glucose impairment (diabetic situation) ${ }^{11}$.

Insulin plant also called as Costus igneus, family Costaceae is an extensively known for its therapeutic potential. Leaf part of this plant has possessed abundant antidiabetic potential. According to the Ayurveda, daily consumption of one leaf can bring the glucose level normal 12,13. To balance the glucose level, patients are advised to take anti-diabetic drugs (herbal extract or marketed drug). There might be cases, patients will be administering both i.e. Aripiprazole (prescribed drug) and Insulin plant leaves or extracts without informing practitioners. For primary level understanding of HDIs present study was designed and inhibitory effect of IPE on CYP2D6 examined.

\section{MATERIALS AND METHODS:}

21 Chemicals, reagents and solvents: Aripiprazole was received as a gift sample from FTF Pharma, India. Quercetin was procured from Sigma laboratory. Chloroform, Dichloromethane, Absolute Ethanol, Formaldehyde, Methanol, Isopropyl alcohol, Ethyl acetate, Petroleum ether, Acetonitrile was used during the study. All solvents (analytical grade) were purchased from the E-Merck and Fisher Scientific laboratories. The major instruments used for the study are described as follows: Analytical balance (Mettler Toledo JB1603), Rotavapour (Buchi Rotavapor R-210), Filtration Pump (Millipore vaccum), Stirrer (REMI $3 \mathrm{MLH}$ and Eltech digimag), Melting point apparatus (Veego VMP-DS), Infrared (IR) spectrophotometer [ShimadzuERS-8000 Fourier Transform (FT-IR)], Homogeniser (Polytron, PT2500E), HPLC (LC-2010 HT, Shimadzu), Refrigerated Centrifuge model Universal 320 R (Hettich), Refrigerated ultracentrifuge (OPTIMA max-XP ultracentrifuge), UV/Visible Spectrophotometer (Shimadzu-1800, Japan), Water bath (Yorco), Dry bath (Yorco), Shaker (Orbitek, Scigenics).

22 Collection of the plant material: Insulin plant was received as a gift sample from one nursery of Pune, Maharashtra (Fig. 1). Authentication of the plant was done by Dr. Hitesh Solnaki, Professor, Gujarat University, and Ahmedabad, India.

23 Preparation of Insulin plant extract: After authentication, leaves were collected, dried at room temperature for 2-3 days (Fig. 2) and powdered. Weighed out the powder material and kept it with solvent (Methanol) for 24 hours then filtered and concentrated each filtrate fraction by rotavapor 14 . Extract of methanol indicated the presence of Quercetin which was compared with the standard Quercetin by TLC. Percentage yield of extract was calculated. An extract was dried and kept in aluminium coated polyethylene bags.
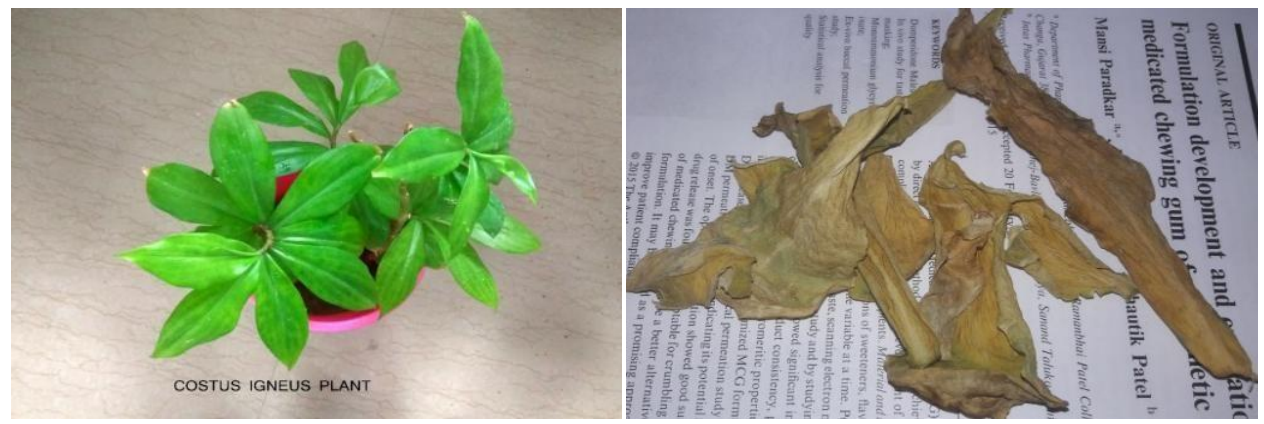

Fig.1. Insulin plant

Fig.2. Leaves after Drying 


\section{Chemical Characterization:}

2.4.1 Chemical characterization of prepared extract:

241.1 Preliminary phytochemical screening: Extract of Insulin plant was subjected to phytochemical tests to determine the presence of active secondary metabolite using standard procedures 15 .

2412 HPLC studies for standardization of plant extract: Methanolic extract was characterized qualitatively and quantitatively through HPLC for this, ACN: MQ (3pH) was used as mobile phase. Accurately weighed $25 \mathrm{mg}$ of standard Quercetin was transferred to a $25 \mathrm{ml}$ volumetric flask and dissolved in Methanol. Volume make up was done with methanol to obtain standard stock solution of concentration $1000 \mu \mathrm{g} / \mathrm{ml}$, and diluted for next required samples. Same procedure was followed for extract.

2413 UV spectroscopy of Methanolic extract: $10 \mathrm{mg}$ of Quercetin was dissolved in $100 \mathrm{ml}$ of methanol. From this, different dilutions were prepared in the concentration of $2,4,6,8,10$, and $12 \mu \mathrm{g} / \mathrm{ml}$.

2.4.2 Characterization of Aripiprazole: Characterization of Aripiprazole was done using HPLC, UV spectrophotometry, IR and melting points.

2421 HPLC: HPLC was done to determine the purity of the selected drug. Aripiprazole was dissolved in the respective solvents of analytical grade and HPLC analysis was performed (Table 1).

Table1: HPLC conditions for Aripiprazole

\begin{tabular}{|l|l|}
\hline Drug & Aripiprazole \\
\hline Mobile phase & $\begin{array}{l}\text { Acetonitrile : Ammonium acetate } \\
(90: 10 \mathrm{~V} / \mathrm{V})\end{array}$ \\
\hline Reported $\lambda$ max & $214 \mathrm{~nm}$ \\
\hline Detector & Photodiode array (PDA) detector \\
\hline Injection volume & $5 \mu \mathrm{l}$ \\
\hline Column & C18 Kromasil \\
\hline
\end{tabular}

2422 Absorbance maxima determination: An Absorbance maximum of Aripiprazole was determined after dissolving in methanol.

2423 Melting point and FTIR spectroscopy determination: Melting point determination of Aripiprazole was performed using Melting point apparatus. For IR study, Aripiprazole pellet was prepared and finger printing was taken out.

25 Isolation of rat liver microsome: Swiss Wistar strain rats (120-15 g) were used in this procedure. The study was approved by the Animal ethical committee affiliated to the National Institute of Pharmaceutical Education and Research Institutional Animal Ethical Committee (NIPER-A/IAEC/2017/031/R). Rat was anesthetised using Xylazine, sacrificed and liver was isolated and perfused with the $1.15 \% \mathrm{KCl}$. In the next step, homogenization was done with the help of homogenizer, and sample was allowed for centrifuged at $9600 \mathrm{rpm}$ for 20 minute at $4^{\circ} \mathrm{C}$. Further, ultracentrifuged was carried out at 1, 05,000 rpm for 30 minute at $4^{\circ} \mathrm{C}$. Pellets formed were transferred in sample tube and stored at $-80^{\circ} \mathrm{C}$ in fridge until use [16].

26 Development of calibration curve using Bovine Serum Albumin (BSA) and protein estimation using Bradford method: 96 well plates were employed for this study. For calibration curve; $210 \mu$ l reaction mixture containing $200 \mu \mathrm{l}$ of Bradford reagent, $8 \mu \mathrm{l}$ of water and $2 \mu \mathrm{l}$ of BSA was taken. $10 \mu \mathrm{l}$ of water and $200 \mu \mathrm{l}$ of Bradford reagent used as control. Water and BSA concentration were varying from $2 \mu \mathrm{l}-10 \mu \mathrm{l}$ and absorbance took at $595 \mathrm{~nm}$. Each concentration was reported in triplicate [17].

27 Measurement of effects of extract in the combination with Aripiprazole on CYP2D6 using HPLC: Determination of Aripiprazole and Dehydroaripiprazole was done using reported HPLC method [18]. Briefly, chromatographic separations were carried out on RP C- 18 kromasil column $(250 \mathrm{~mm}$ $\times 4.6 \mathrm{~mm}, 5 \mu \mathrm{m}$ particle size) using Acetonitrile and Ammonium acetate $(90: 10, \mathrm{v} / \mathrm{v})$ as a mobile phase for $15 \mathrm{~min}$ with the flow rate of $1 \mathrm{ml} / \mathrm{min}$ using photodiode array detector (PDA). Aripiprazole was used as a probe substrate and formation of Dehydroaripiprazole was used as a measure of CYP2D6 activity. Briefly, in sample tubes $250 \mu \mathrm{L}$ reaction mixture containing $10 \mu \mathrm{L}$ phosphate buffer $(\mathrm{pH} 7.4), 10 \mu \mathrm{L}$ of test samples (extract $20-1000 \mu \mathrm{g} / \mathrm{ml}$ ), $10 \mu \mathrm{L}$ of Aripiprazole $(5 \mu \mathrm{g} / \mathrm{mL})$ and $205 \mu \mathrm{L}$ of RLM were added. The reaction was initiated with the addition of $25 \mu \mathrm{L}$ of Nicotinamide adenine Dihydrogen phosphate (NADPH-2mMol/L). Followed by, it was incubated in a shaking water bath at $37{ }^{\circ} \mathrm{C}$ for $15 \mathrm{~min}$. The reaction was stopped by the addition of ice-cold $100 \mu \mathrm{L}$ of methanol and mixture was extracted with the $1 \mathrm{~mL}$ of ice-cold ethyl acetate, which was then vigorously vortexed for $2 \mathrm{~min}$ and centrifuged at 13,000 rpm for 5 minutes. An organic phase was transferred into a clean tube and evaporated to dryness under a nitrogen stream. The residue was reconstituted in $100 \mu \mathrm{L}$ mobile phase and used for the HPLC analysis and assay was performed in triplicate.

28 Calculation of Inhibitory concentration (IC $\left.{ }_{50}\right)$ Value:

$\%$ control activity $=($ Peak area of Dehydroaripiprazole in the presence of extract/peak area of Dehydroaripiprazole in control) $\times 100$ and $\%$ inhibitory activity $=100-\%$ control activity was calculated using these formula. IC50 value was calculated from the Graph Pad Prism5. The graph was obtained between log concentration and $\%$ of inhibitory.

\section{RESULTS:}

3.1 Determination of Percentage yield: The percentage yield of IPE was found to be $10.845 \%$ (W/W)

32 Chemical characterization of prepared extract:

3.2.1 Preliminary phytochemicals screening: TLC for extract has been performed with respect to the suitable mobile phase. Methanolic extract was found to be enriched with Quercetin as analytical marker (Fig.3 \& Fig.4). Further, quantification was carried out in next step. 


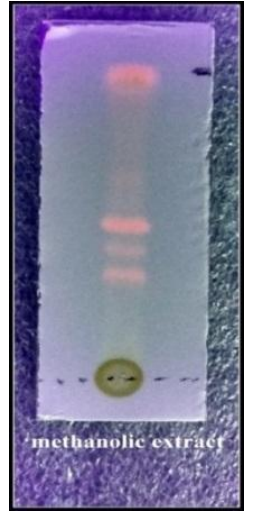

Fig.3. TLC of Methanolic leaves extract

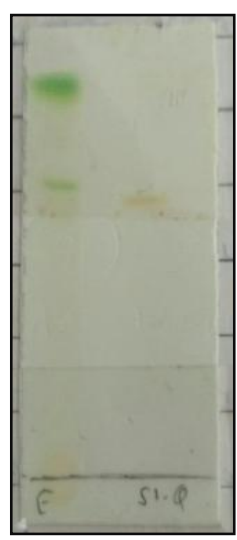

Fig. 4. TLC of Methanolic extract with standard Quercetin<smiles>O=c1c(O)c(-c2ccc(O)c(O)c2)oc2cc(O)cc(O)c12</smiles>

Fig.5. Chemical structure of Quercetin

3.2. HPLC studies for standardization of plant extract: HPLC revealed the presence of Quercetin in the IPE (Table $2 \& 3$ ).

Table 2 HPLC conditions for extract standardization

\begin{tabular}{|l|l|}
\hline Extract & Methanolic \\
\hline Mobile phase & $\begin{array}{l}\text { Acetonitrile }: \text { MQ with } 3 \mathrm{pH} \text { (HPLC grade) } \\
(60: 40 \mathrm{~V} / \mathrm{V})\end{array}$ \\
\hline Reported $\lambda$ max & $253 \mathrm{~nm}$ \\
\hline Detector & Photodiode array (PDA) detector \\
\hline Injection volume & $5 \mu \mathrm{l}$ \\
\hline Column & Kinetica C18 \\
\hline Run time & 10 minute \\
\hline
\end{tabular}

Table 3 HPLC observations for standard and extract Quercetin

\begin{tabular}{|c|c|c|c|c|c|}
\hline Sr. No. & Name & Rt & Wavelength & Area & Peak purity \\
\hline 1 & Quercetin & 12.6 & $253 \mathrm{~nm}$ & 1719606 & 0.980497 \\
\hline 2. & molic extract of Insulin plant & 13.42 & $253 \mathrm{~nm}$ & 392489 & 1 \\
\hline
\end{tabular}

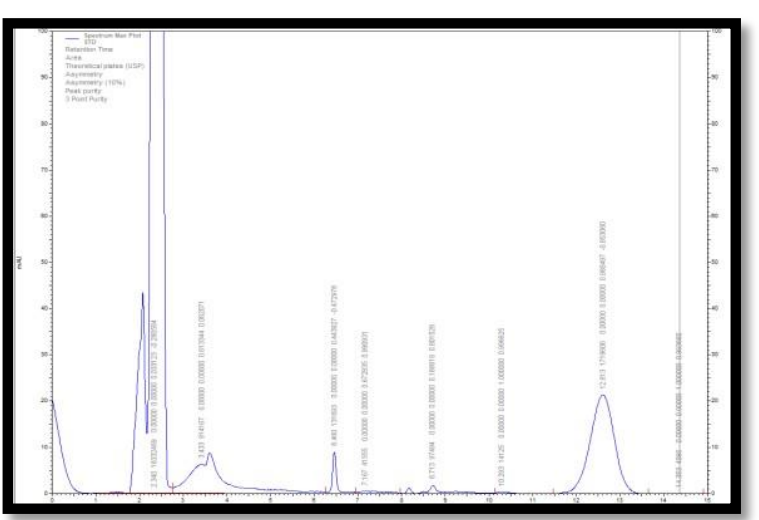

Fig.6. HPLC chromatogram of standard Quercetin

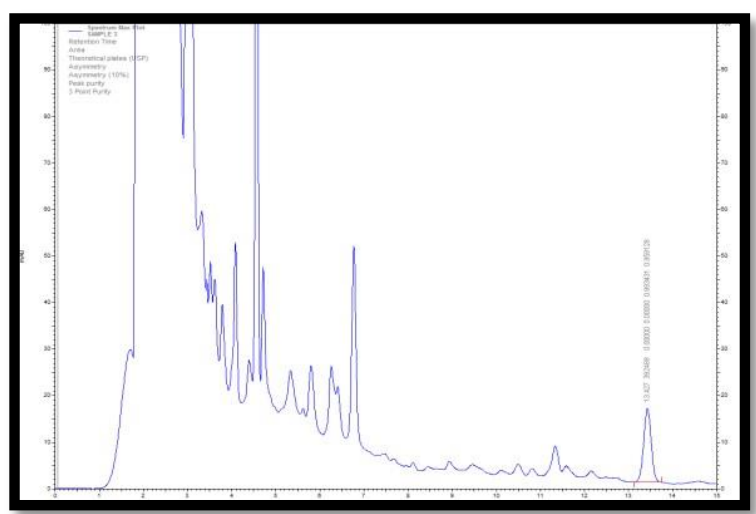

Fig.7. HPLC chromatogram of Quercetin for extract 


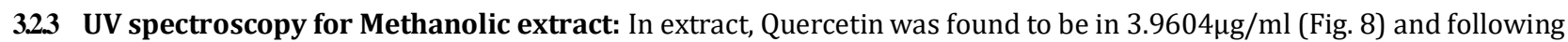
table summarizes about dilutions (Table 4).

Table 4 Quantitative estimation of Quercetin using UV

\begin{tabular}{|c|c|}
\hline Concentration $(\boldsymbol{\mu g} / \mathbf{m l})$ & Absorbance \\
\hline 2 & 0.117 \\
\hline 4 & 0.262 \\
\hline 6 & 0.412 \\
\hline 8 & 0.535 \\
\hline 10 & 0.670 \\
\hline 12 & 0.804 \\
\hline
\end{tabular}

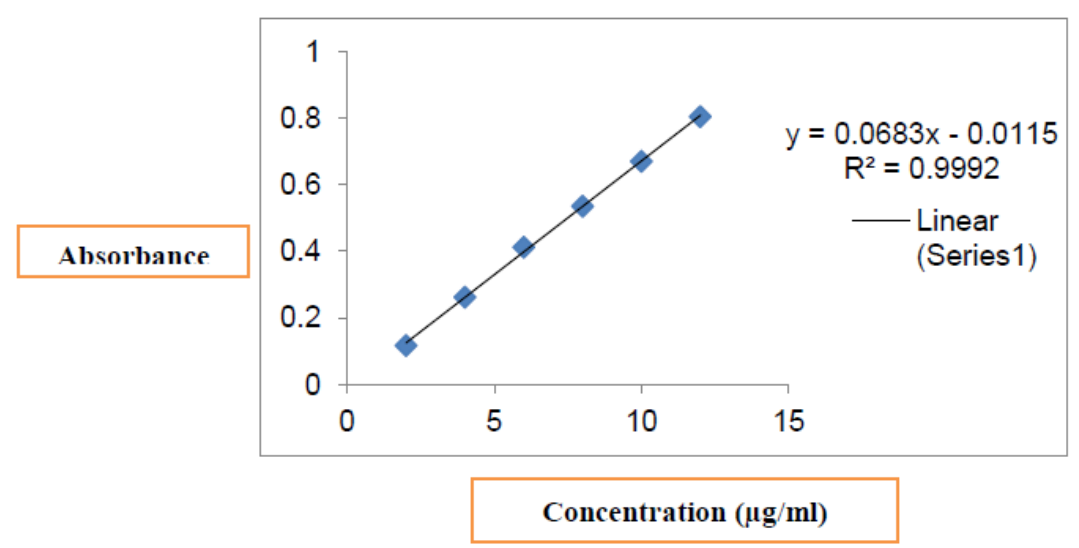

Fig.8. Calibration curve plotted using standard Quercetin<smiles>O=C1CCc2ccc(OCCCCN3CCN(c4cccc(Cl)c4Cl)CC3)cc2N1</smiles>

Fig.9. Chemical structure of Aripiprazole

3.3.1 HPLC of Aripiprazole: Following chromatogram was observed (Fig. 10)

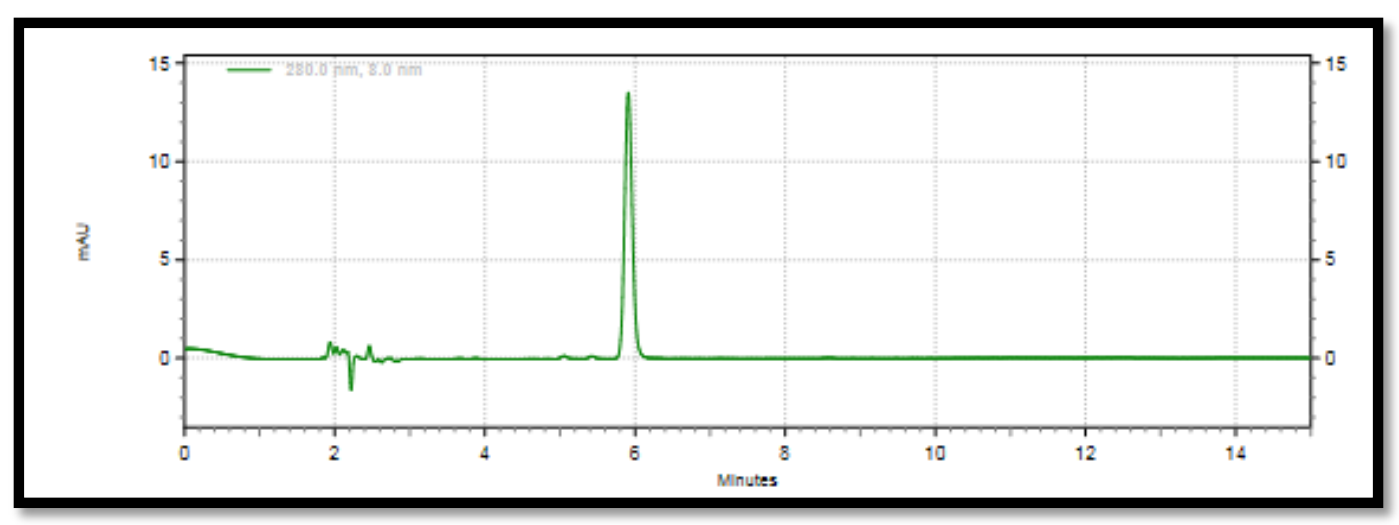

Fig.10. Chromatogram of Aripiprazole 
3.3.2 Absorbance maxima determination: To check the purity of Aripiprazole, absorbance maxima was done. Absorbance was measured in spectrum mode (Fig. 11).

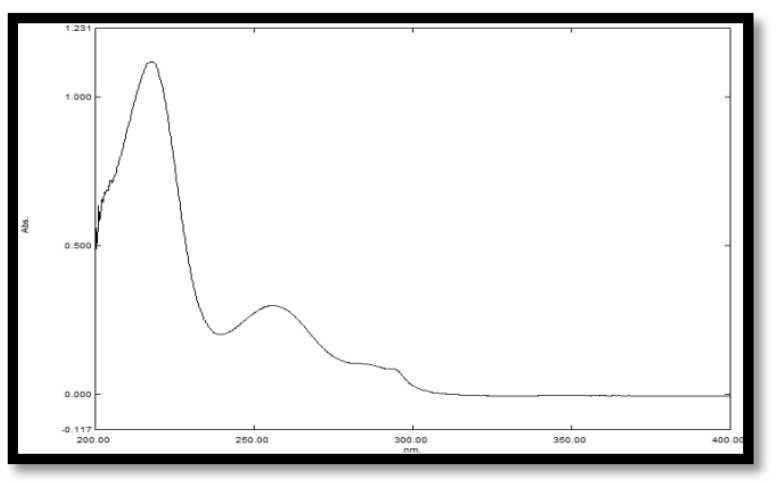

Fig.11. UV Spectrum of Aripiprazole

3.3.3 Melting point and IR spectra determination: Following (Table 5) described melting point observation. And finger print is shown on (Fig.12).

Table 5 Melting point of substrate Aripiprazole

\begin{tabular}{|c|c|l|}
\hline Substrate & Reported melting point & \multicolumn{1}{|c|}{ Observed melting point } \\
\hline Aripiprazole & $139.0-139.5^{\circ} \mathrm{C}$ & $139.0^{\circ} \mathrm{C}$ \\
\hline
\end{tabular}

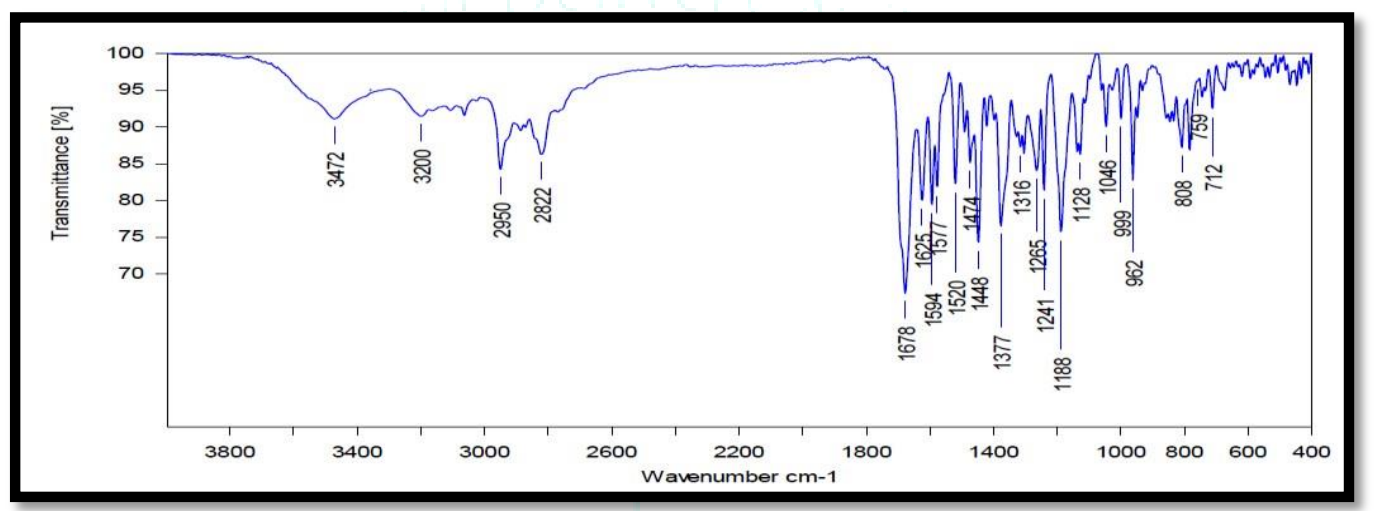

Fig.12. IR spectra for Aripiprazole

3.3.4 Protein estimation by Bradford method: Protein estimation was done and following table (Table 6) and graph was observed (Fig.13).

Table 6 Protein estimation absorbance

\begin{tabular}{|c|c|}
\hline Concentration $(\mu \mathrm{g} / \mathrm{ml})$ & Absorbance \\
\hline 2 & 0.158 \\
\hline 4 & 0.307 \\
\hline 6 & 0.447 \\
\hline 8 & 0.508 \\
\hline 10 & 0.62 \\
\hline
\end{tabular}

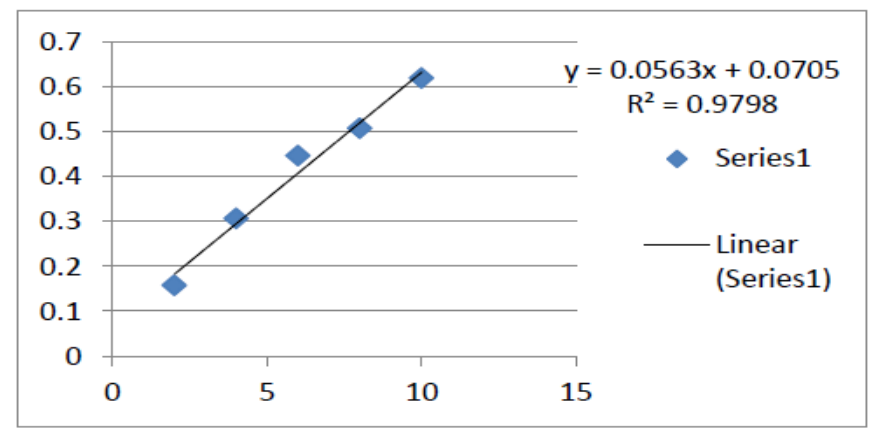

Fig. 13. Calibration curve plotted of standard BSA 
3.3.5 Measurement of the inhibitory effects of IPE in combination with Aripiprazole on CYP2D6 using HPLC: Following graphs show the presence of Aripiprazole peak and there was no peaks changes (shift, presence, absence) were noted, when Aripiprazole was treated with the IPE and RLM.

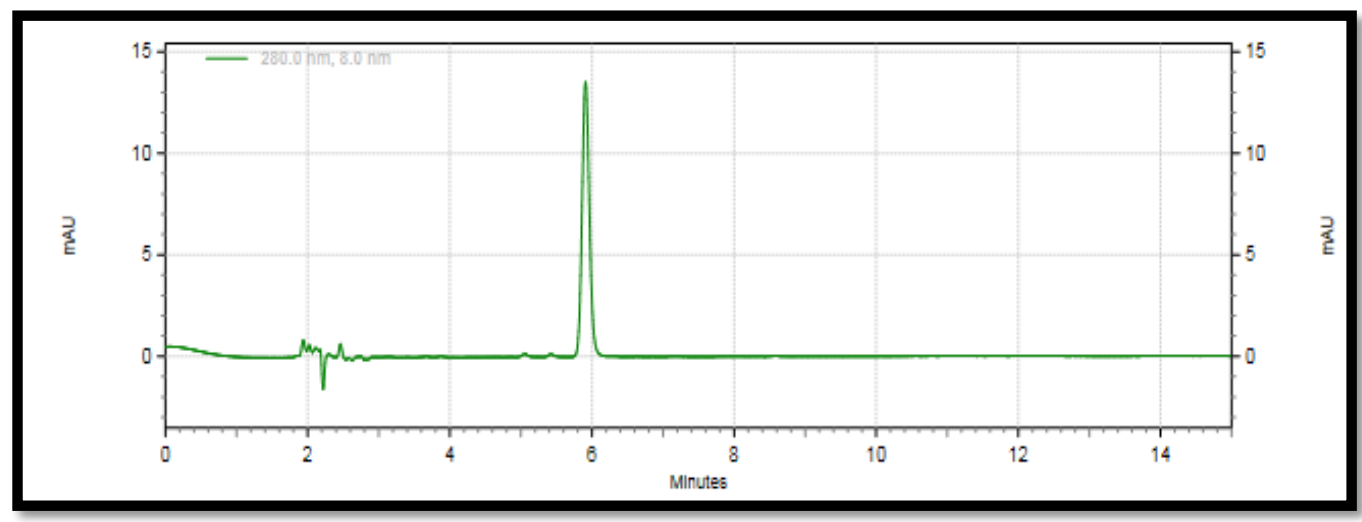

Fig.14. Chromatogram of Aripiprazole using HPLC

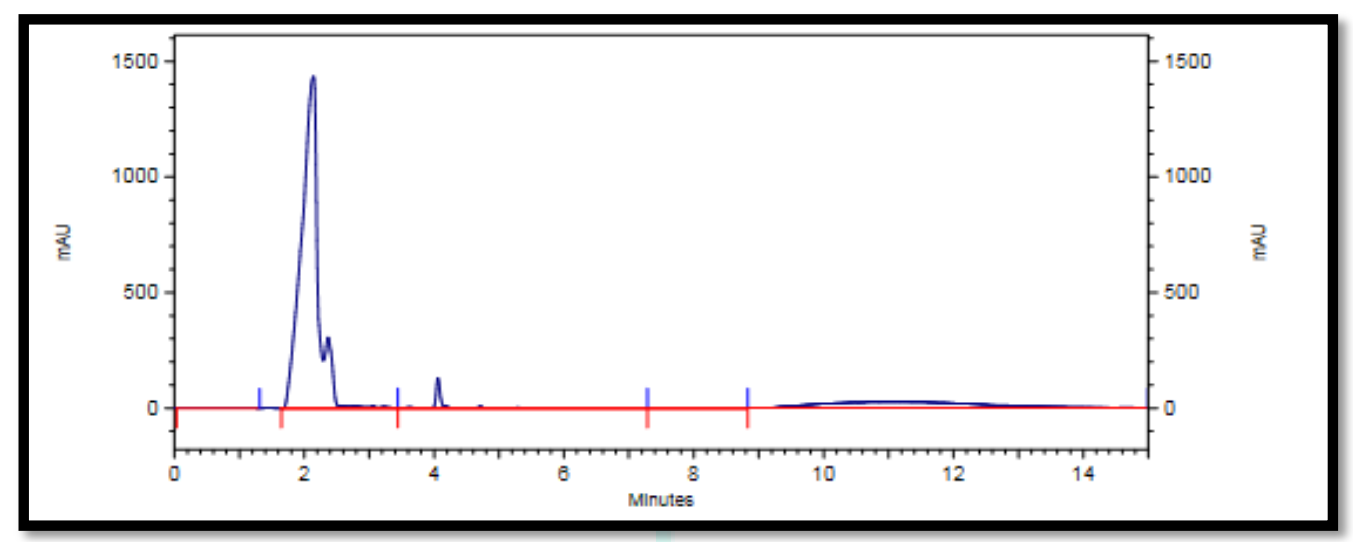

Fig.15. Mixture of only Aripiprazole + rat liver microsome

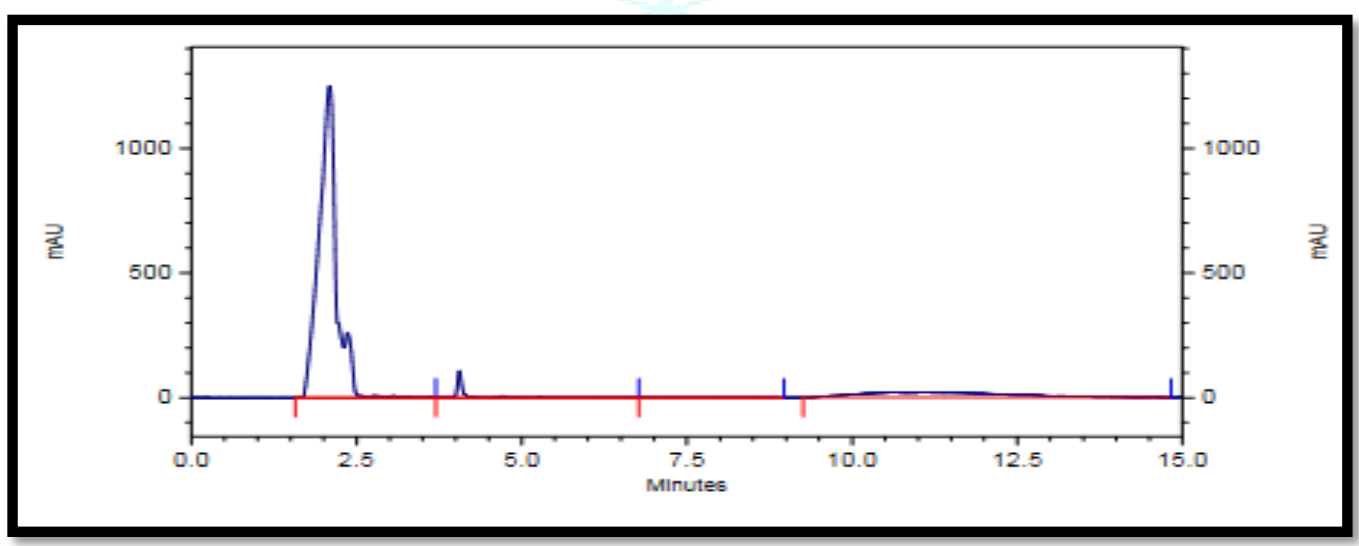

Fig.16. Mixture of Aripiprazole + RLM + IPE-200 $\mathrm{gg} / \mathrm{ml}$

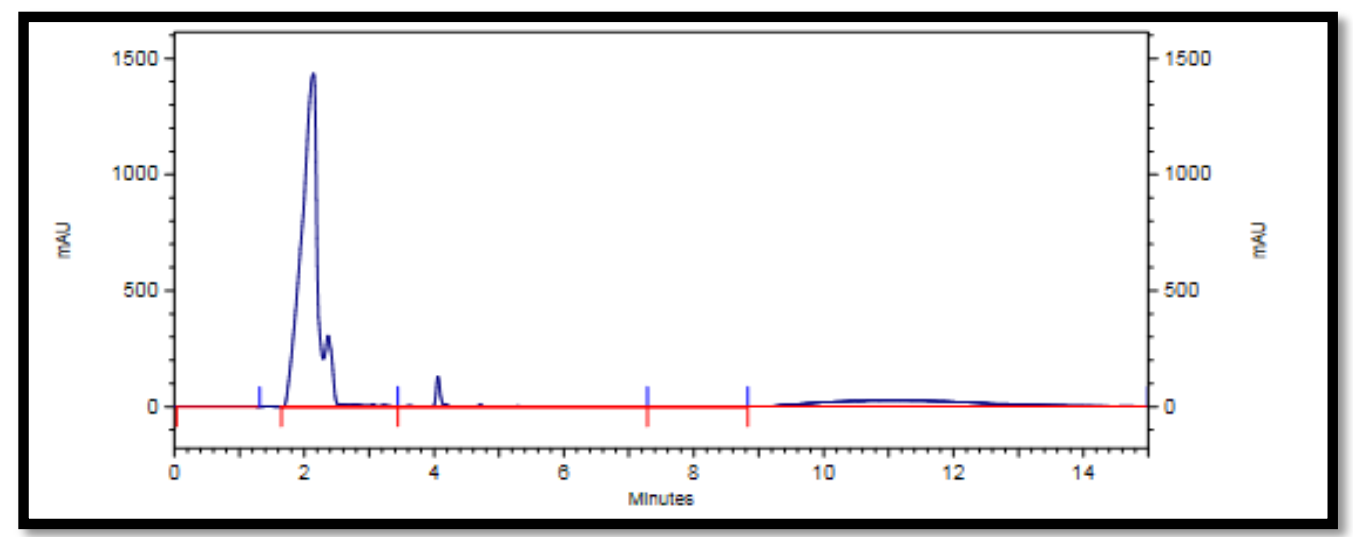

Fig.17. Aripiprazole + RLM + IPE-400 $\mu \mathrm{g} / \mathrm{m}$ 


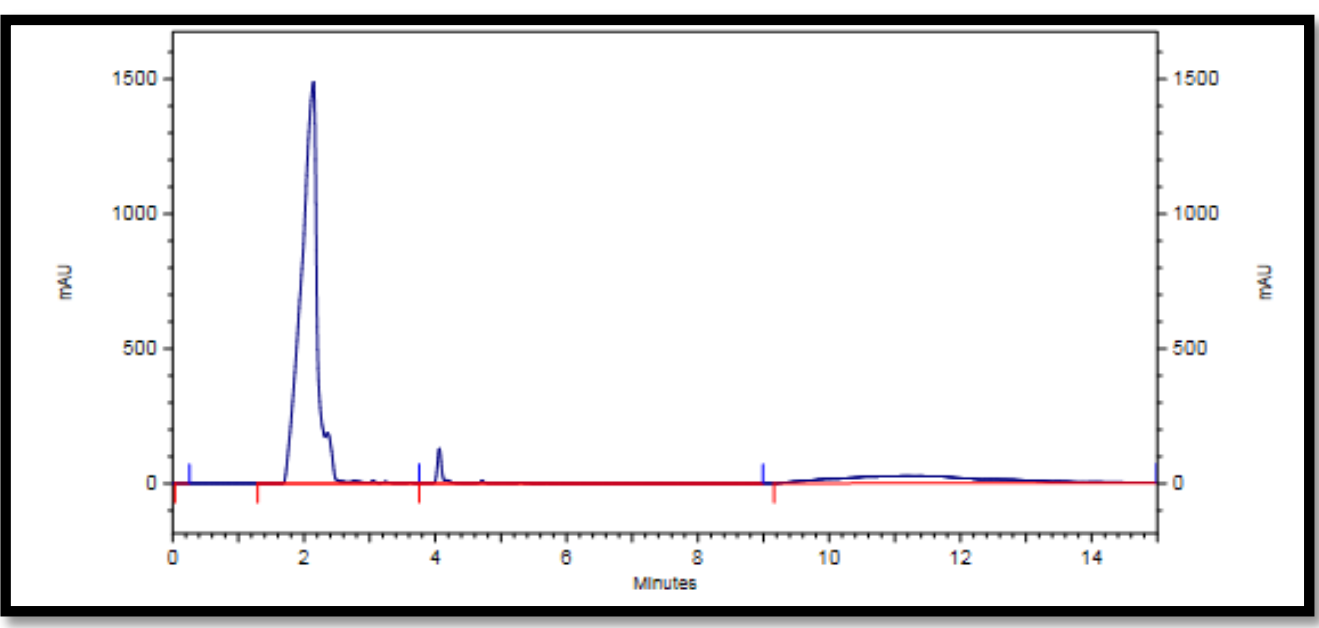

Fig.18. Mixture of Aripiprazole + RLM + IPE- $600 \mu \mathrm{g} / \mathrm{ml}$

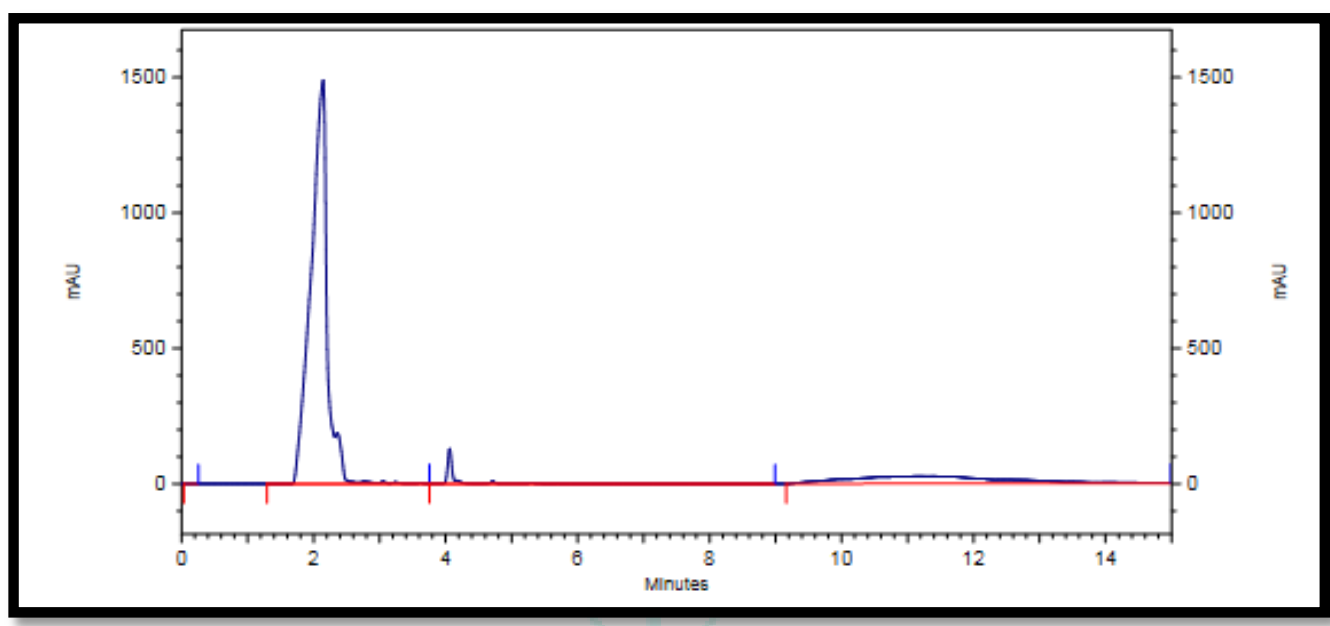

Fig.19. Mixture of Aripiprazole + RLM + IPE-800 $\mu \mathrm{g} / \mathrm{ml}$

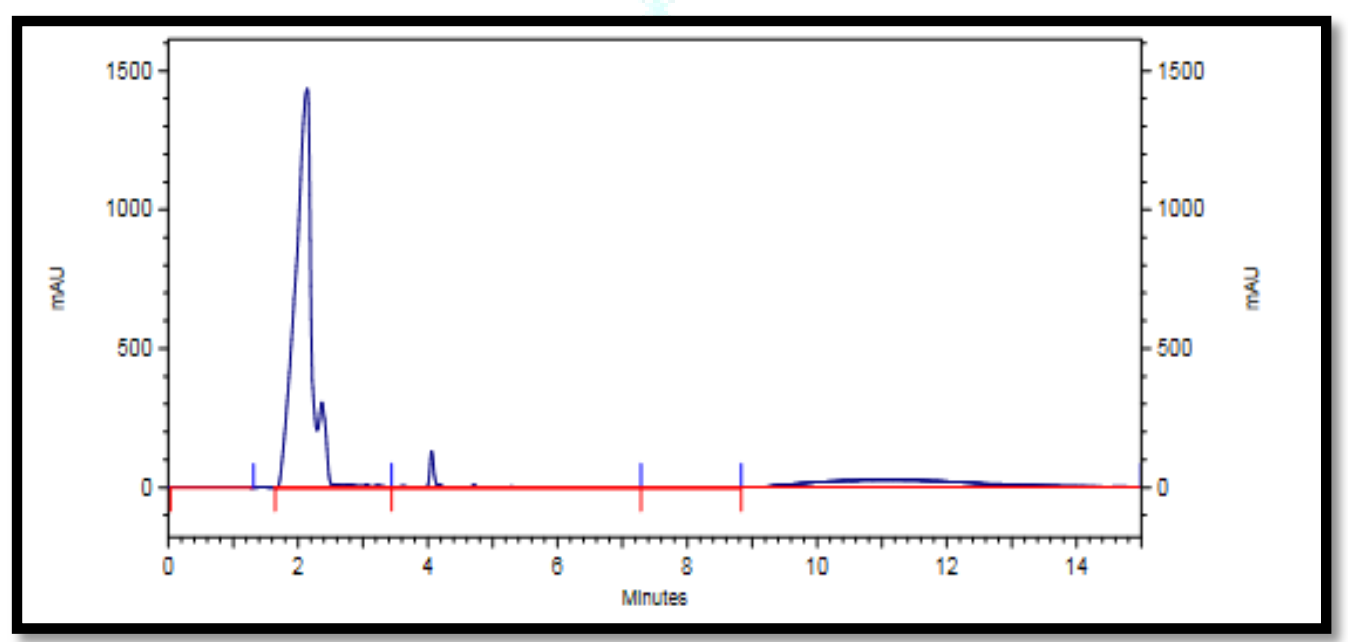

Fig.20. Mixture of Aripiprazole + RLM + IPE-1000 $\mu \mathrm{g} / \mathrm{ml}$

Table 7 Effect of different concentration of IPE on CYP2D6

\begin{tabular}{|c|c|}
\hline Log concentration $(\mu \mathrm{g} / \mathrm{ml})$ & Inhibition \\
\hline 4.301 & $0.1070 \pm 0.0065$ \\
\hline 4.602 & $0.2210 \pm 0.0076$ \\
\hline 4.778 & $0.2688 \pm 0.0096$ \\
\hline 4.903 & $0.5515 \pm 0.075$ \\
\hline 5 & $0.2211 \pm 0.0083$ \\
\hline
\end{tabular}

Data are represented as mean \pm standard $(n=3)$ 


\section{DISCUSSION:}

IPE was prepared by the successive extraction method. Further, Preliminary phytochemical screening was performed and Methanolic extract was found to be enriched with the analytical marker Quercetin. TLC was performed with the standard Quercetin and retention factor (Rf) value was found to be 0.6. Qualitative and quantitative determination was done using HPLC and UV which was found to be $3.96 \mu \mathrm{g} / \mathrm{ml}$. Additionally, characterization of Aripiprazole was carried out. In the next step, RLM were isolated and kept at $-80^{\circ} \mathrm{C}$ and protein concentration was found to be $2.92 \mu \mathrm{g} / \mathrm{ml}$ using BSA as standard. HPLC study showed that no significant changes were observed in the retention time $\left(\mathrm{R}_{\mathrm{t}}\right)$ of Aripiprazole when incubated along with the IPE and $\mathrm{RLM}$, and $\mathrm{IC}_{50}$ value was found to be $4.49 \mu \mathrm{g} / \mathrm{ml}$ (Table 8).

\section{CONCLUSION:}

This research narrows down the path of scientists working in the same field. Our work suggests that IPE did not show any significant CYP2D6 inhibition even at the concentration equivalent to the highest clinical dose after oral administration i.e., $20-1000 \mu \mathrm{g} / \mathrm{ml}$. The $\mathrm{IC}_{50}$ value of extract of Insulin plant has been found to be below $1000 \mu \mathrm{g} / \mathrm{mL}$ Since Ayurvedic physicians typically use much lower doses of these extracts than the doses used here hence, the chances of interactions (inhibitory) are very rare.

Future perspective: This study (primary level observations) opens a door for the scientist working in the same area to look ahead. Evidence of In vitro followed by in vivo, will be much helpful to avoid any clinical challenges. Study of pharmacokinetic parameters for IPE will be good approach to track and reveal the HDIs.

Acknowledgement: Authors are thankful to the Department of Pharmaceutical, ministry of chemicals and Fertilizers, Government of India for providing scholarship to Harshita Gupta. Authors would like to acknowledge nursery from Pune who was kind enough to send the plant to carry out research work.

\section{Conflict of interests: None.}

\section{REFERENCES}

1 Oga, E. F. et al. Pharmacokinetic herb-drug interactions: insight into mechanisms and consequences, European journal of drug metabolism and pharmacokinetics. Springer. 2016; 41(2):93108. https://doi.org/10.1007/s13318-015-0296-z

2 Zhou, S.-F. et al. Identification of drugs that interact with herbs in drug development, Drug discovery today. Elsevier. 2007; 12(15-16):664-673.

https://doi.org/10.1016/j.drudis.2007.06.004

3 Chung, V.C. H. et al. Do patients tell their clinicians they are using both prescribed and over the counter allopathic and traditional medicines? European Journal of Integrative Medicine.
Elsevier. 2011; 3(4):e289-e298.

https://doi.org/10.1016/j.eujim.2011.09.008

4 Hu, Z. et al. Herb-drug interactions, Drugs. Springer. 2005; 65(9):1239-1282. https://doi.org/10.2165/00003495200565090-00005

5 Fugh-Berman, A. Herb-drug interactions, The Lancet. Elsevier. 2000; 355(9198):134-138. https://doi.org/10.1016/S01406736(99) 06457-0

6 Services, U. S. D. of H. and H. Guidance for Industry: Drug interaction studies-study design, data analysis, implications for dosing, and labeling recommendations, Food and Drug Administration, Center for Drug Evaluation and Research (CDER), 2012; 39-40.

7. Kamble, B. et al. Determination of gymnemagenin in rat plasma using high-performance liquid chromatography-tandem mass spectrometry: application to pharmacokinetics after oral administration of Gymnema sylvestre extract, Biomedical Chromatography. Wiley Online Library. 2013; 27(5):669-675. https://doi.org/10.1002/bmc.2845

8 Shapiro, D. A. et al. Aripiprazole, a novel atypical antipsychotic drug with a unique and robust pharmacology, Neuropsychopharmacology. Nature Publishing Group. 2003; 28(8):1400. https://doi.org/10.1038/sj.npp.1300203

9. "Product information for Abilify Aripiprazole Tablets \& Orally Disintegrating Tablets". TGA eBusiness Services. Bristol-Myer Squibb Australia pvt Ltd. 1 November 2012. Retrieved 22 October 2013.

10. "Abilify (Aripiprazole) - Clinical Pharmacology".DrugLib.com. 14 February 2007. Retrieved 8 December 2008.

11 "Abilify". The American society of Health-System Pharmacists. Retrieved 3 April 2011.

12 Raaz K Maheshwari, Bhanwar Lal Jat, Urmila Choudhary, Rajnee Bina Rani. Biomedicinal sovereignty of prunes for gastrointestinal ailments therapy. International journal of medicinal and pharmaceutical research, 2014; 2(3):669-674.

13. Satyanarayan ND, Mohammedsiraj mirji, Anantacharya and sanjeevkumar Giri. Amylase inhibitory activity of costus igneus leaf extract. International research journal of pharmaceutical and applied sciences, 2015; 1(5):12-15.

14. Kala, S. Antimicrobial Activity of Coleus For skohlii (Wild) Briq and Costus igneus NE Br. Journal of Pharmacy and Biological Science. 2014; 9:01-06.

15. Devi D, Urooj A. Nutrient profile and antioxidant components of Costus speciosus Sm. And Costus igneus Nak. Indian Journal of Natural Products and Resources. 2010; 1(1):116-8.

16 Borse SP, Kamble BB. Effect of Ayurvedic Rasayana botanicals on CYP3A4 isoenzyme system. Journal of Integrative medicine, 2015; 13(3): 165-172. https://doi.org/10.1016/S20954964(15)60173-X

17. Lee C. A. et al. CYP3A4 expressed by insect cells infected with a recombinant baculovirus containing both CYP3A4 and human NADPH-Cytochrome $\mathrm{P} 450$ reductase is catalytically similar to human liver microsomal CYP3A4, Archives of Biochemistry and Biophysics. Elsevier, 1995; 319(1):157-167. https://doi.org/10.1006/abbi.1995.1278

18 Thakkar R. S. et al. A chromatographic determination of Aripiprazole using HPLC and UPLC: A comparative validation study, Indian journal of pharmaceutical sciences. Medknow Publications. 2011; 73(4):439. https://dx.doi.org/10.4103\%2F0250-474X.95638 